\title{
A Simplified Stress Analysis of Functionally Graded Beams and Influence of Material Function on Deflection
}

\author{
Fadi Althoey ${ }^{1}$ (D) and Elias Ali ${ }^{2, *(\mathbb{D})}$ \\ 1 Department of Civil Engineering, College of Engineering, Najran University, Najran 1988, Saudi Arabia; \\ fmalthoey@nu.edu.sa \\ 2 Department of Civil and Environmental Engineering, The University of Alabama in Huntsville, \\ Huntsville, AL 35805, USA \\ * Correspondence: elias.ali@uah.edu
}

Citation: Althoey, F.; Ali, E. A Simplified Stress Analysis of Functionally Graded Beams and Influence of Material Function on Deflection. Appl. Sci. 2021, 11, 11747. https://doi.org/10.3390/ app112411747

Academic Editor: Victor Franco Correia

Received: 22 November 2021 Accepted: 9 December 2021 Published: 10 December 2021

Publisher's Note: MDPI stays neutral with regard to jurisdictional claims in published maps and institutional affiliations.

Copyright: (c) 2021 by the authors. Licensee MDPI, Basel, Switzerland. This article is an open access article distributed under the terms and conditions of the Creative Commons Attribution (CC BY) license (https:// creativecommons.org/licenses/by/ $4.0 /)$.

\begin{abstract}
This paper aims at providing a simplified analytical solution for functionally graded beam stress analysis and optimized material gradation on the beam deflection. The power-law (P-FGM) and exponential (E-FGM) material functions were considered for an exact solution of the normal and shear stress distributions across the beam thickness. Optimization of material function on the FGM beam deflection, which is new of its kind, was also investigated considering both simply supported and cantilever beams. It was observed that the non-dimensional normal stress and shear stress are independent of the elastic moduli values of the constituent materials but rather depends on both the ratio of the elastic moduli and the location across the beam thickness in the E-FGM material function model. This observation was first validated from available kinds of literature and through numerical simulation using ABAQUS and extended to the P-FGM stress analysis. The maximum deflection on the FGM beam occurred for a homogenous steel beam while the minimum deflection was observed on the beam with a P-FGM material function. The results of this work demonstrate that if properly designed and optimized, FGMs can provide an alternative material solution in structural applications.
\end{abstract}

Keywords: functionally graded material; volume fraction; normalized stress; material functions

\section{Introduction}

Functionally graded materials (FGMs) are a new class of advanced composite materials that possess gradually varying material properties within a given direction. FGMs can be manufactured by varying the constituent multi-phase of two or more parent materials in a predetermined profile. This gradation can be achieved by either combining two or more materials using volume fraction or by treating a single material chemically to change its initial properties. The functionally graded composite material will then have a different and unique property while preserving benefits from individual parent materials. Considered as the "holy grail" of composite materials, in the last three decades, FGMs have been extensively been used in areas of aerospace, medicine, defense, energy, and optoelectronics industries [1] while their application as a structural component is still in its infancy.

Many studies on FGM beams subjected to mechanical and thermal loading are available in the literature. The first attempt on an elasticity solution of FGM beams subjected to static transverse loads was proposed in [2] assuming the beam properties to vary throughthickness following an exponential law. A new beam finite element analysis was developed in [3] and investigated the thermo-elastic behavior of functionally graded beam structures based on first-order shear deformation theory and accounting for varying elastic and thermal properties along with the beam thickness. A combined Fourier series and Galerkin method for solving the two-dimensional elasticity equations for a functionally graded beam subjected to transverse loads using a polynomial function to account for the variation of Young's modulus through the beam thickness was reported in [4]. Finite element method 
for characterizing the dynamic free vibration of a functionally graded beam with material graduation axially or transversely through the thickness based on the power-law function and a finite element method to study the static behavior of Timoshenko FGM cantilever beam subjected to a concentrated load at the free end and using power law for varying material properties through-beam thickness was investigated and proposed in $[5,6]$. The static behavior of functionally graded metal-ceramic beams under transverse loading using higher-order shear deformation theory, assuming power-law function to account for material variation through-beam thickness was studied in [7]. Nonlinear bending approximate solution of FGM beam was reported in [8] using higher-order shear deformation theory and based on beam physical neutral surface. The beam material properties were assumed to be temperature-dependent and vary through-thickness. The exact free vibration and buckling analysis of tapered beam-column made of FGM material and assumed the P-FGM material variation along with the cross-section's height and the vibration behavior of composite coupled conical shell structures were presented in [9-11]. FGM beam bending solution for Timoshenko beams compared with those of Euler-Bernoulli beams is also presented in [12]. Deformation analysis of functionally graded beams by using a direct approach and linear bending of FGM beams by the differential quadratic method were investigated in [13,14]. A new insight on the potential application of FGM for an extreme environment such as for fire protection was presented in $[15,16]$. There has also been a significant interest in FGM plate analysis through both analytical and finite element investigation such as in [17-20]. Literature on FGM beams under arbitrarily distributed loading, crack growth, and bilayer FGM cantilever beams are also available in [21-23].

Even though there are numerous kinds of literature on FGM beam analysis, many only focus on the FE method of analysis and use only E-FGM material models in the analysis. Thus, this paper aims to provide a simplified method and solution for FGM beam normal and shear stress analysis considering two material functions, power-law (P-FGM) and exponential (E-FGM). Also, the influence of material functions on FGM beam deflection was investigated through analytical solution considering simply supported and cantilever FGM beams which exhibited a smaller deformation compared with homogenous steel beams of the same size and similar loadings. The results and observation from this study would make it easier for practicing engineers on understanding the stress distribution through FGM beam thickness and lead to better choice in material selection.

\section{Mechanical Properties of Functionally Graded Materials}

FGMs are advanced composite materials with a mixture of ceramic and metal or a combination of different metals made by gradually varying the volume fraction of the constituent materials. The functionally graded material can be continually produced by varying the constituent multi-phase materials in a predetermined profile. The constitutive material property which varies with a given direction is expressed using volume fraction variation. This volume fraction variation can be described using the power-law function, sigmoid function, or exponential function.

\subsection{Power-Law Material Function (P-FGM)}

The volume fraction variation of the FGM beam in the power-law function can be expressed with Equation (1) within a given direction, where $\mathrm{z}$ is any point within a given direction, $\mathrm{h}$ is the total thickness (width), and $\mathrm{n}$ is a power-law index parameter.

$$
f(z)=\left(\frac{z+h / 2}{h}\right)^{n}
$$

$f(z)$ is the variation of volume fraction for one of the two constituent materials making up the FGM matrix. This means the second material will have a volume fraction of $1-f(z)$ at a given location across a thickness (if the desired graduation is within a thickness direction). It can also be noticed that for every power-index value (n) considered, the FGM matrix will have $100 \%$ of one material at the top and $100 \%$ of the second material at the 
bottom of the beam cross-section. Once the local volume fraction is defined, the functional relation of material properties at any point across the thickness can be expressed according to the general rule of mixtures. The Young's modulus variation $\mathrm{E}(\mathrm{z})$ within beam thickness for P-FGM can be calculated by using Equation (2).

$$
\mathrm{E}(\mathrm{z})=\mathrm{E}_{1} \mathrm{f}(\mathrm{z})+(1-\mathrm{f}(\mathrm{z})) \mathrm{E}_{2}
$$

where $E_{1}$ and $E_{2}$ are Young's moduli of the FGM at the bottom (h/2) and top (-h/2) surfaces.

\subsection{Sigmoid Material Function (S-FGM)}

Chung and Chi [24] developed volume fractions using two power-law functions to create a smooth distribution of stresses among all interfaces wherein the case of adding an FGM of a single power-law function to multi-layered composite, stress concentration appears on one of the interfaces [25]. The volume fraction variation of FGM in sigmoid function can be expressed with Equations (3) and (4) along the thickness direction which is divided into two parts of the FGM thickness. The parameter (p) designates a parameterindex in S-FGM.

$$
\begin{gathered}
\mathrm{f}_{1}(\mathrm{z})=1-\frac{1}{2}\left(\frac{\frac{\mathrm{h}}{2}-\mathrm{z}}{\frac{\mathrm{h}}{2}}\right)^{\mathrm{p}} \quad \text { for } \quad 0 \leq \mathrm{z} \leq \frac{\mathrm{h}}{2} \\
\mathrm{f}_{2}(\mathrm{z})=\frac{1}{2}\left(\frac{\frac{\mathrm{h}}{2}+\mathrm{z}}{\frac{\mathrm{h}}{2}}\right)^{\mathrm{p}} \text { for } \quad-\frac{h}{2} \leq \mathrm{z} \leq 0
\end{gathered}
$$

The Young's modulus variation in the S-FGM can be calculated using a similar expression as P-FGM but uses volume fraction for each part separately as shown in Equations (5) and (6).

$$
\begin{array}{ccc}
E(z)=f_{1}(z) E_{1}+\left[1-f_{1}(z)\right] E_{2} & \text { for } & 0 \leq z \leq \frac{h}{2} \\
E(z)=f_{2}(z) E_{1}+\left[1-f_{1}(z)\right] E_{2} & \text { for } & -\frac{h}{2} \leq z \leq 0
\end{array}
$$

\subsection{Exponential Material Function (E-FGM)}

The exponential function is the most used FGM material function among many researchers due to its simplicity in obtaining analytical solutions and the only parameter is the natural logarithm of the ratio of elastic modulus of the two materials considered. Equation (7) is used to describe the variation of elastic modulus in E-FGM.

$$
\mathrm{E}(\mathrm{z})=\mathrm{E}_{2} \mathrm{e}^{\beta \mathrm{z}}
$$

where $\beta=\frac{1}{h} \ln \left(\frac{E_{1}}{E_{2}}\right)$.

The young's modulus variation within the FGM beam thickness for P-FGM and E-FGM material functions is presented in Figure 1.

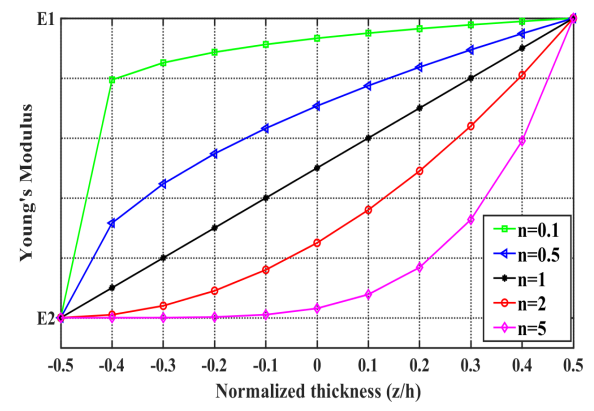

(a)

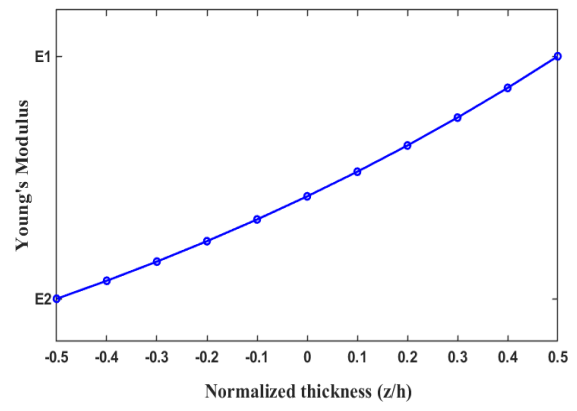

(b)

Figure 1. Variation of Young's modulus in (a) P-FGM and (b) E-FGM. 


\section{Analytical Approach to FGM Beam Analysis}

A simplified analytical formulation for functionally graded beam stresses analysis is presented in this section. The material properties in the FGM beam were assumed to vary in the thickness direction using power-law (P-FGM) and exponential function (E-FGM) material functions.

\section{The Mathematical Formulation for FGM Beam Analysis}

Consider a functionally graded beam with a rectangular cross-section shown in Figure 2 with length $L$, width $b$, and depth $h$. To simplify the FGM beam stress analysis, the following assumptions were made: (1) FGM beam is modeled with classical Euler-Bernoulli beam theory, where mid-plane remains undeformed; (2) Poisson ratio is assumed constant along with the beam thickness; and (3) normal stress in z-z axis is neglected.

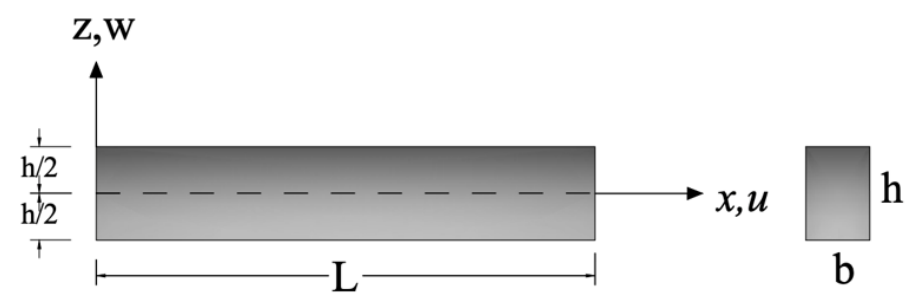

Figure 2. The geometry of the functionally graded beam. Where $\mathrm{h}, \mathrm{b}$ and $\mathrm{L}$ are beam cross-section width, depth and length respectively.

The axial and transverse displacement fields can be expressed as in Equation (8), which are derived from [3].

$$
\mathrm{u}(\mathrm{x}, \mathrm{z})=\mathrm{u}_{0}(\mathrm{x})+\mathrm{z} \phi(\mathrm{x}) \mathrm{w}(\mathrm{x}, \mathrm{z})=\mathrm{w}_{0}(\mathrm{x})
$$

where $\varnothing$ is the first derivative of the transverse displacement.

The constitutive relation of the FGM beam can be assumed to obey Hook's law and can be written as

$$
\{\sigma\}=\left\{\begin{array}{c}
\sigma_{\mathrm{xx}} \\
\tau_{\mathrm{xz}}
\end{array}\right\}=\left[\begin{array}{cc}
\mathrm{E}(\mathrm{z}) & 0 \\
0 & \mathrm{G}(\mathrm{z})
\end{array}\right]\left\{\begin{array}{l}
\varepsilon_{\mathrm{xx}} \\
\gamma_{\mathrm{xz}}
\end{array}\right\}
$$

where $\sigma_{\mathrm{xx}}$ and $\varepsilon_{\mathrm{xx}}$ are normal stresses and normal strains in the x-direction and $\tau_{\mathrm{xz}}$ and $\gamma_{\mathrm{xz}}$ are the shear stress and shear strain in the $x-z$ plane. $E(z)$ and $G(z)$ are the Young's and shear moduli, which are functions of the FGM beam depth $z$.

The axial strain can be expressed using Equation (10).

$$
\varepsilon_{\mathrm{x}}=\varepsilon_{\mathrm{x} 0}+\mathrm{z} \kappa
$$

where $\varepsilon_{\mathrm{x} 0}, \kappa$ and $\mathrm{z}$ are the normal strain at mid-plain, the curvature, and the distance from the neutral axis of the FGM beam. Using the Euler-Bernoulli beam theory, the resultant axial force $(\mathrm{N})$ and bending moment $(\mathrm{M})$ can be evaluated using Equations (11) and (12).

$$
\begin{aligned}
& \mathrm{N}=\int \sigma_{\mathrm{x}} \mathrm{dA} \\
& \mathrm{M}=\int \mathrm{z} \sigma_{\mathrm{x}} \mathrm{dA}
\end{aligned}
$$

Substituting Equations (9) and (10) into Equations (11) and (12), the resultant forces can be expressed including the material variation through the beam thickness.

$$
N=\int E(z)\left(\varepsilon_{x 0}+z \kappa\right) d z
$$




$$
\mathrm{M}=\int \mathrm{zE}(\mathrm{z})\left(\varepsilon_{\mathrm{x} 0}+\mathrm{z \kappa}\right) \mathrm{dz}
$$

Equations (13) and (14) can further be related using the matrix form below

$$
\left[\begin{array}{l}
\mathrm{N} \\
\mathrm{M}
\end{array}\right]=\left(\begin{array}{ll}
\mathrm{K}_{1} & \mathrm{~K}_{2} \\
\mathrm{~K}_{2} & \mathrm{~K}_{3}
\end{array}\right)\left\{\begin{array}{c}
\varepsilon_{\mathrm{x} 0} \\
\kappa
\end{array}\right\}
$$

where $K_{1}, K_{2}$ and $K_{3}$ are stiffness coefficients and can be expressed as

$$
\begin{aligned}
\mathrm{K}_{1} & =\int \mathrm{E}(\mathrm{z}) \mathrm{dz} \\
\mathrm{K}_{2} & =\int \mathrm{zE}(\mathrm{z}) \mathrm{dz} \\
\mathrm{K}_{3} & =\int \mathrm{z}^{2} \mathrm{E}(\mathrm{z}) \mathrm{dz}
\end{aligned}
$$

The inverse relation for Equation (15) can be written as

$$
\left\{\begin{array}{c}
\varepsilon_{\mathrm{x} 0} \\
\kappa
\end{array}\right\}=\left(\begin{array}{ll}
\mathrm{K}_{1} & \mathrm{~K}_{2} \\
\mathrm{~K}_{2} & \mathrm{~K}_{3}
\end{array}\right)^{-1}\left[\begin{array}{l}
\mathrm{N} \\
\mathrm{M}
\end{array}\right]=\left(\begin{array}{ll}
\mathrm{K}_{1}^{*} & \mathrm{~K}_{2}{ }^{*} \\
\mathrm{~K}_{2} * & \mathrm{~K}_{3}^{*}
\end{array}\right)\left[\begin{array}{l}
\mathrm{N} \\
\mathrm{M}
\end{array}\right]
$$

where $\mathrm{K}_{1}{ }^{*}, \mathrm{~K}_{2}{ }^{*}$ and $\mathrm{K}_{3}{ }^{*}$ are the inverse stiffness coefficients.

$$
\begin{aligned}
\mathrm{K}_{1}^{*} & =\frac{\mathrm{K}_{3}}{\mathrm{~K}_{1} \mathrm{~K}_{2}-\mathrm{K}_{2}^{2}} \\
\mathrm{~K}_{2}{ }^{*} & =\frac{-\mathrm{K}_{2}}{\mathrm{~K}_{1} \mathrm{~K}_{2}-\mathrm{K}_{2}^{2}} \\
\mathrm{~K}_{3}{ }^{*} & =\frac{\mathrm{K}_{1}}{\mathrm{~K}_{1} \mathrm{~K}_{2}-\mathrm{K}_{2}^{2}}
\end{aligned}
$$

Since the axial force resultant $N=0$; the strain at mid-plane and the curvature can have the form

$$
\begin{gathered}
\varepsilon_{\mathrm{x} 0}=\mathrm{K}_{2}{ }^{*} \mathrm{M}(\mathrm{x}) \\
\kappa=\mathrm{K}_{3}{ }^{*} \mathrm{M}(\mathrm{x})
\end{gathered}
$$

Substituting Equations (23) and (24) into Equation (10) and then into Equation (9) the axial stress distribution across the FGM beam thickness at any location $(x)$ when subjected to $\mathrm{M}(\mathrm{x})$ can be obtained as:

$$
\sigma_{\mathrm{xx}}(\mathrm{x}, \mathrm{z})=\mathrm{K}_{3}{ }^{*} \mathrm{E}(\mathrm{z}) \mathrm{M}(\mathrm{x})\left(\frac{\mathrm{K}_{2}{ }^{*}}{\mathrm{~K}_{3}{ }^{*}}+\mathrm{z}\right)
$$

Since the axial stress is zero at the FGM beam N.A., one can recognize that the N.A. for the FGM beam is located at

$$
\mathrm{z}=-\frac{\mathrm{K}_{2}{ }^{*}}{\mathrm{~K}_{3}{ }^{*}}
$$

The transverse shear stress can be obtained by integrating the equilibrium equation

$$
\frac{\partial \sigma_{x x}}{\partial x}+\frac{\partial \tau_{x z}}{\partial z}=0
$$

An expression for the shear stress at a distance $\mathrm{z}$ can be obtained as:

$$
\tau_{\mathrm{xz}}(\mathrm{x}, \mathrm{z})=-\int_{0, \mathrm{~h} / 2}^{\mathrm{z} *} \frac{\partial \sigma_{\mathrm{xx}}}{\partial \mathrm{x}} \mathrm{dz}
$$


Substituting the axial stress expression in Equation (25) into Equation (28), one can obtain the FGM shear stress distribution across the beam thickness.

$$
\tau_{\mathrm{xz}}(\mathrm{x}, \mathrm{z})=-\int_{0, \mathrm{~h} / 2}^{\mathrm{z} *} \frac{\partial\left[\mathrm{K}_{3}{ }^{*} \mathrm{E}(\mathrm{z}) \mathrm{M}(\mathrm{x})\left(\frac{\mathrm{K}_{2}{ }^{*}}{\mathrm{~K}_{3}{ }^{*}}+\mathrm{z}\right)\right]}{\partial \mathrm{x}} \mathrm{dz}
$$

It should be noted from the limit of integration in Equation (29) that, depending on the material function, one can choose the reference axis for material variation in the FGM beam. The shear stress distribution can further be simplified as Equation (30). Where Vz is the resultant shear force at a given location along beam length.

$$
\tau_{\mathrm{xz}}(\mathrm{x}, \mathrm{z})=-\mathrm{V}_{\mathrm{z}}\left[\int_{0, \mathrm{~h}, 2}^{\mathrm{z} *}\left(\mathrm{~K}_{2}{ }^{*} \mathrm{E}(\mathrm{z})+\mathrm{zK}_{3}{ }^{*} \mathrm{E}(\mathrm{z})\right) \mathrm{dz}\right]
$$

\section{Results and Discussion}

The results from a simplified analytical formulation for functionally graded beam normalized axial and shear stresses distributions are presented in detail in this section. The material properties in the FGM beam were assumed to vary in the thickness direction using power-law (P-FGM) and exponential function (E-FGM) material functions. The FE model was also conducted using ABAQUS and some of the results obtained were validated by comparing with those kinds of literature. Young's modulus for metal $\left(E_{1}\right)$ and ceramic $\left(E_{2}\right)$ considered were $210 \mathrm{GPa}$ (29500-ksi) and $390 \mathrm{GPa}$ (55114-ksi), respectively. The Poisson ratio was assumed to be constant for each layer with a value of 0.3 as suggested in [2].

\subsection{Exponential Function FGM Beam}

The material function in the E-FGM beam is expressed using Equation (7). Explicit expressions for FGM beam stiffness coefficients can be solved by integrating Equations (16)-(18) using the limit of integration from 0 to $z$ where $E_{1}$ and $E_{2}$ are the elastic moduli of the FGM beam at the $(\mathrm{z} / \mathrm{h}=0)$ and $(\mathrm{z} / \mathrm{h}=1)$.

$$
\begin{gathered}
\mathrm{K}_{1}=\frac{\mathrm{h}\left(\mathrm{E}_{1}-\mathrm{E}_{2}\right)}{\ln \left(\frac{\mathrm{E}_{1}}{\mathrm{E}_{2}}\right)} \\
\mathrm{K}_{2}=-\left(\mathrm{h}^{2}\left(\mathrm{E}_{1}-\mathrm{E}_{2}\right)-\mathrm{E}_{1} \mathrm{~h}^{2} \ln \left(\frac{\mathrm{E}_{1}}{\mathrm{E}_{2}}\right)\right) /\left(\ln \left(\frac{\mathrm{E}_{1}}{\mathrm{E}_{2}}\right)\right)^{2} \\
\mathrm{~K}_{3}=\left(2 \mathrm{~h}^{3}\left(\mathrm{E}_{1}-\mathrm{E}_{2}\right)-2 \mathrm{E}_{1} \mathrm{~h}^{3} \ln \left(\frac{\mathrm{E}_{1}}{\mathrm{E}_{2}}\right)+\mathrm{E}_{1} \mathrm{~h}^{3} \ln \left(\frac{\mathrm{E}_{1}}{\mathrm{E}_{2}}\right)^{2}\right) /\left(\ln \left(\frac{\mathrm{E}_{1}}{\mathrm{E}_{2}}\right)\right)^{3}
\end{gathered}
$$

Substituting the inverse of stiffness coefficients and $\mathrm{E}(\mathrm{z})$ one can obtain the axial normal stress and shear stress distributions across E-FGM beam thickness normalized to the normal stress at beam top-end and average shear stress for normal and shear distribution respectively.

\subsubsection{Axial Stress Distribution in E-FGM Beam}

The axial stress distribution across the FGM beam thickness at any location (x) when subjected to $\mathrm{M}(\mathrm{x})$ for any applied load can be obtained using Equation (25) and the corresponding results are presented in Figure 3. It can be observed that the non-dimensional normal stress is independent of the actual elastic moduli values, but rather depends on the ratio of $E_{1} / E_{2}$ and the location across the beam thickness (z). This means that, regardless of the material types, the normalized stress distribution is mainly influenced by the ratio of the elastic moduli of constituent materials. From the stress distribution, it can also be observed that the normal stress is zero at $\mathrm{z} / \mathrm{h}=0.5$ for $\mathrm{E}_{1} / \mathrm{E}_{2}=1.0$, at about $\mathrm{z} / \mathrm{h}=0.672$, 
$\mathrm{z} / \mathrm{h}=0.625, \mathrm{z} / \mathrm{h}=0.444$, and $\mathrm{z} / \mathrm{h}=0.3275$ for $\mathrm{E}_{1} / \mathrm{E}_{2}=10, \mathrm{E}_{1} / \mathrm{E}_{2}=5, \mathrm{E}_{1} / \mathrm{E}_{2}=0.5$, and $\mathrm{E}_{1} / \mathrm{E}_{2}=0.1$ respectively. These points also correspond to the neutral axis locations for the FGM beam.

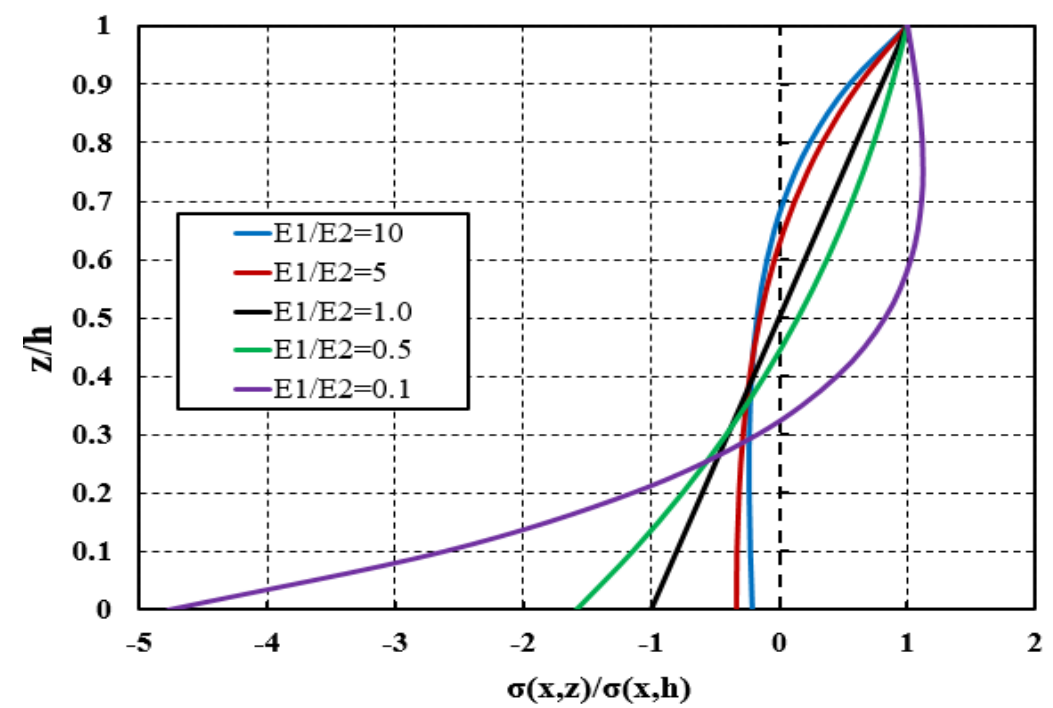

Figure 3. Normalized Axial stress $\sigma x x$ distribution in simply supported E-FGM beam.

\subsubsection{Shear Stress Distribution in E-FGM Beam}

Similarly, the shear stress distribution in the FGM beam was evaluated using Equation (30). From the normalized shear stress distribution, as shown in Figure 4, it is evident that the maximum normalized shear stress is in the neutral axis locations for each $E_{1} / E_{2}$ considered. Moreover, the normalized shear stress is 1.5 times the average shear stress for $E_{1}=E_{2}$, which is consistent with the classical beam theory. However, this maximum ratio is 1.68 , $1.55,1.49$, and 1.62 for $E_{1} / E_{2}=10, E_{1} / E_{2}=5, E_{1} / E_{2}=0.5$, and $E_{1} / E_{2}=0.1$, respectively. This observation implies that an FGM beam could withstand more shear stress than a homogenous and isotropic beam.

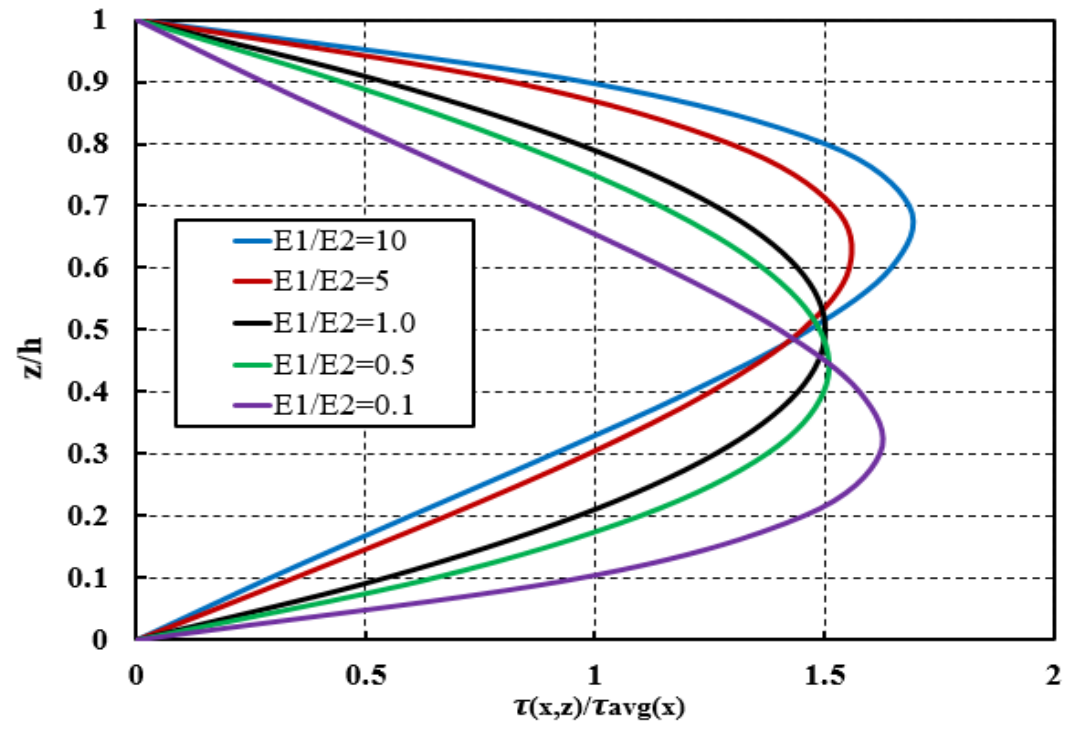

Figure 4. Normalized Shear stress $\tau x z$ distribution in simply supported E-FGM beam.

To validate the results presented above for E-FGM beam axial stress, a numerical simulation was performed using ABAQUS and compared with results from [2] and [26]. The FGM beams were modeled in ABAQUS with a step-wise material gradation from ceramic at top of the beam $(\mathrm{Ec}=390 \mathrm{MPa})$ to steel $(\mathrm{Es}=210 \mathrm{MPa})$ using 16-layers $(6.25 \mathrm{~mm}$ 
thick each layer) across the $10 \mathrm{~cm}$ thickness of the beam where each layer is assumed to be isotropic and homogenous based on the volume fraction. The ABAQUS model is shown in Figure 5.

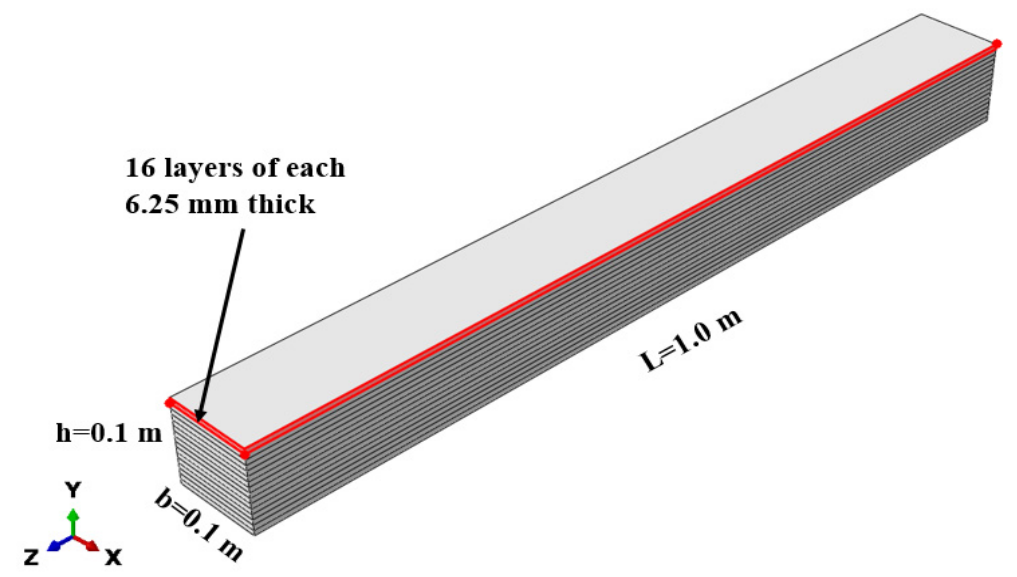

Figure 5. Numerical modeling of FGM beam in ABAQUS.

An eight-node linear brick with a reduced integration element type (C3D8R) with a mesh size of $5 \mathrm{~mm}$ was used for discretization. A simply-supported boundary condition was considered in the model and a uniformly distributed load of $1 \mathrm{KN} / \mathrm{m}$ was applied on the beam top face. Mesh sensitivity was first performed for mesh sizes of $10 \mathrm{~mm}, 7.5 \mathrm{~mm}$, $5.0 \mathrm{~mm}$, and $2.0 \mathrm{~mm}$ with corresponding stress ratios the top and bottom beam flexural stresses shown in Table 1.

Table 1. Mesh size sensitivity.

\begin{tabular}{ccc}
\hline $\begin{array}{c}\text { Mesh Size } \\
(\mathbf{m m})\end{array}$ & $\mathbf{E}_{\mathbf{1}} / \mathbf{E}_{\mathbf{2}}=\mathbf{1 0}$ & $\mathrm{E}_{\mathbf{1}} / \mathrm{E}_{\mathbf{2}}=\mathbf{0 . 1}$ \\
\hline 2.0 & -0.25 & -4.65 \\
5.0 & -0.244 & -4.60 \\
7.5 & -0.241 & -4.14 \\
10 & -0.237 & -4.20 \\
\hline
\end{tabular}

It can be seen from Figure 6 that the analytical solution for stress distribution presented here for E-FGM agrees well with numerical simulation and with similar literature as shown in Table 2. The comparison was made by considering the ratio of the top and bottom beam normalized flexural stresses along the beam longitudinal axis.

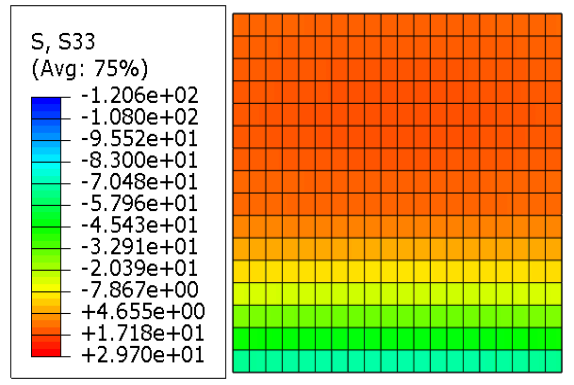

(a)

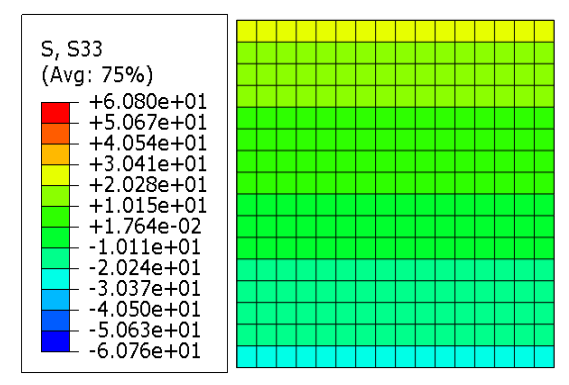

(b)

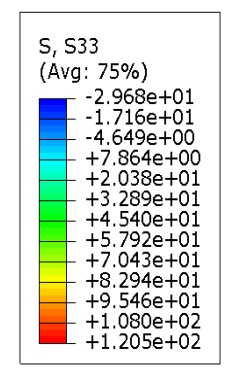

(c)

Figure 6. Numerical models for normal stress distribution in E-FGM beam (a) $E_{1} / E_{2}=10$, (b) $E_{1} / E_{2}=1.0$, and (c) $\mathrm{E}_{1} / \mathrm{E}_{2}=0.1$. 
Table 2. Validation of E-FGM stress distribution.

\begin{tabular}{ccccc}
\hline & This Method & Sankar [2] & $\begin{array}{c}\text { Sharifishourabi et al. } \\
{[26]}\end{array}$ & Numerical Model \\
\hline $\mathrm{E}_{1} / \mathrm{E}_{2}=10$ & -0.209 & -0.21 & -0.209 & -0.24 \\
$\mathrm{E}_{1} / \mathrm{E}_{2}=1.0$ & -1.0 & -1.0 & -1.0 & -1.0 \\
$\mathrm{E}_{1} / \mathrm{E}_{2}=0.1$ & -4.77 & -4.80 & -4.75 & -4.60 \\
\hline
\end{tabular}

The analytical solution well agreed with available literature results in all cases, while a slight difference in the numerical model was observed. The reasons for such differences are, a stepwise material distribution is used in the ABAQUS model, as opposed to continuous variation in the integral of the analytical solution. Furthermore, current commercial software, such as ABAQUS, concentrates on approximate modeling using piecewise homogenous material assignments. Another reason is the number of layers used (sixteen-layers) in a 3D model simulation makes its error susceptible. However, the overall stress distribution in all numerical model cases agrees with the distribution from the analytical solution.

\subsection{Power-Law Function FGM Beam}

The approaches and observation from the E-FGM beam analysis above which is validated from the available literature were used to extend to P-FGM model analysis. The material function in P-FGM is expressed using volume fraction expression in Equation (2) and young's modulus variation from Equation (3). For P-FGM beam analysis the integration is performed from $(-\mathrm{h} / 2)$ to $(\mathrm{h} / 2)$ to obtain the stiffness coefficients of Equations (16)-(18).

$$
\begin{gathered}
\mathrm{K}_{1}=\mathrm{h}\left(\frac{\mathrm{nE_{2 }}+\mathrm{E}_{1}}{\mathrm{n}+1}\right) \\
\mathrm{K}_{2}=\mathrm{nh}^{2}\left(\frac{\mathrm{E}_{1}-\mathrm{E}_{2}}{2(\mathrm{n}+1)(\mathrm{n}+2)}\right) \\
\mathrm{K}_{3}=\frac{\mathrm{h}^{3}}{12}\left(\mathrm{E}_{1}-\frac{12\left(\mathrm{E}_{1}-\mathrm{E}_{2}\right)}{(\mathrm{n}+2)(\mathrm{n}+3)}\right)
\end{gathered}
$$

\subsubsection{Axial Stress Distribution in P-FGM Beam}

Substituting the inverse of the stiffness coefficients, $\mathrm{E}(\mathrm{z})$, and normalizing the stress for the top stress one can obtain the normalized axial normal stress distributions across P-FGM beam thickness as shown in Figure 7. It should be noted that, as opposed to E-FGM analysis, the parameter in P-FGM is the power-law index (n). Therefore, the elastic moduli $E_{1}$ and $E_{2}$ should be initially specified. For this demonstration, $E_{1}=210 \mathrm{MPa}$ and $\mathrm{E}_{2}=390 \mathrm{MPa}$ for steel and ceramic, respectively, were used.

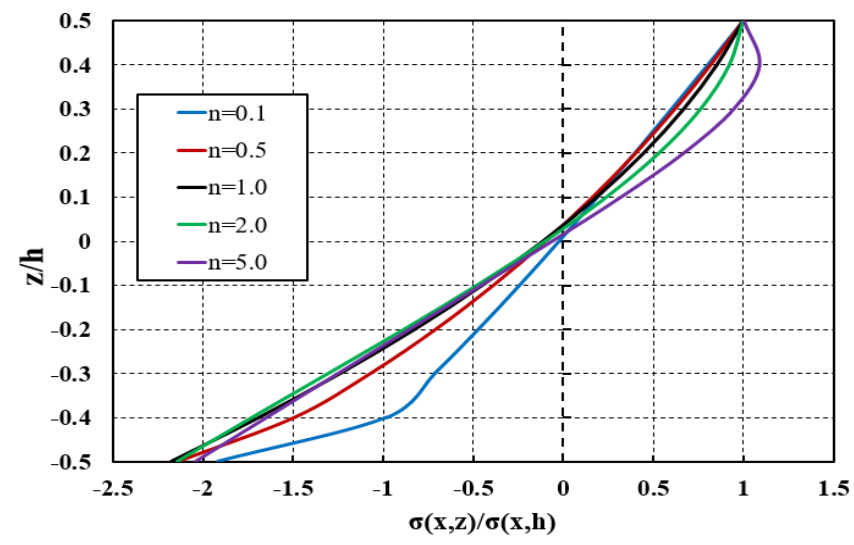

Figure 7. Normalized Axial stress $\sigma x x$ distribution in simply supported P-FGM beam. 


\subsubsection{Shear Stress Distribution in P-FGM Beam}

The shear stress distribution normalized with the average shear stress is presented in Figure 8. One can observe that the maximum shear stress for each power-law index value considered corresponds to the neural axis location along with the beam thickness. For this demonstration $\mathrm{E}_{1}=210 \mathrm{MPa}$ and $\mathrm{E}_{2}=390 \mathrm{MPa}$ for steel and ceramic, respectively, were used. The maximum and minimum normalized shear stress are observed for $\mathrm{n}=0.1$ and $\mathrm{n}=2.0$ with 1.45 and 1.14 times the average shear, respectively.

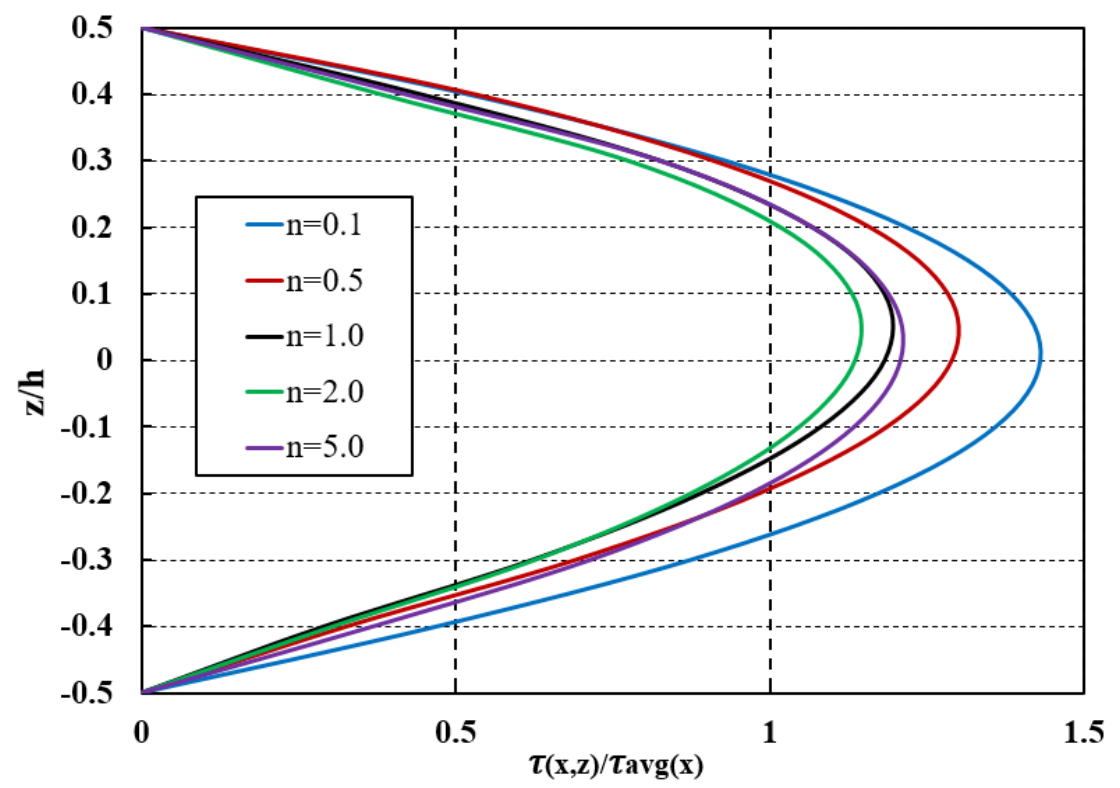

Figure 8. Normalized Shear stress $\tau x z$ distribution in simply supported P-FGM beam.

\subsection{Influence of Material Function on FGM Beam Deflection}

The deflections along the FGM beam $\mathrm{w}(\mathrm{x})$ can be obtained by integrating both sides of the curvature equation for $\mathrm{x}$ and applying boundary conditions. Two boundary conditions were considered: simply supported and Cantilever FGM Beams.

$$
\kappa=\frac{M(x)}{\widetilde{D}}=\frac{d^{2} w}{d x^{2}}
$$

where $\widetilde{\mathrm{D}}$ is the bending rigidity for the FGM beam and can be obtained as

$$
\widetilde{\mathrm{D}}=\mathrm{K}_{3}-\frac{\mathrm{K}_{2}^{2}}{\mathrm{~K}_{1}}
$$

Boundary conditions for simply supported FGM beam:

$$
\mathrm{w}(0)=0 \quad \mathrm{w}(\mathrm{L})=0
$$

Boundary conditions for cantilever FGM beam:

$$
\mathrm{w}(0)=0 \quad \frac{\mathrm{dw}}{\mathrm{dx}}(0)=0
$$

The deflections for both simply supported and cantilever FGM beam was calculated for unit width, $0.1 \mathrm{~m}$ depth, and a total length of $10 \mathrm{~m}$. The S-S beam deflections were analyzed for a unit distributed load while for a cantilever beam a unit concentrated load was applied at the free end. One can observe from Figures 9 and 10 that the maximum deflection occurred for a homogenous steel beam while the minimum deflection is for P-FGM with power-law index value $\mathrm{n}=0.1$ and the E-FGM beam showed the secondlowest deflection in both simply supported and cantilever beams. The reason for this 
can be explained by Young's modulus variation in Figure 1a where for $\mathrm{n}=0.1$ significant portion, about $90 \%$ of the beam thickness, is composed of a material with a higher E-value. The opposite is true for $n=5.0$ where about $80 \%$ of the beam thickness is composed of a material with the smallest E-value.

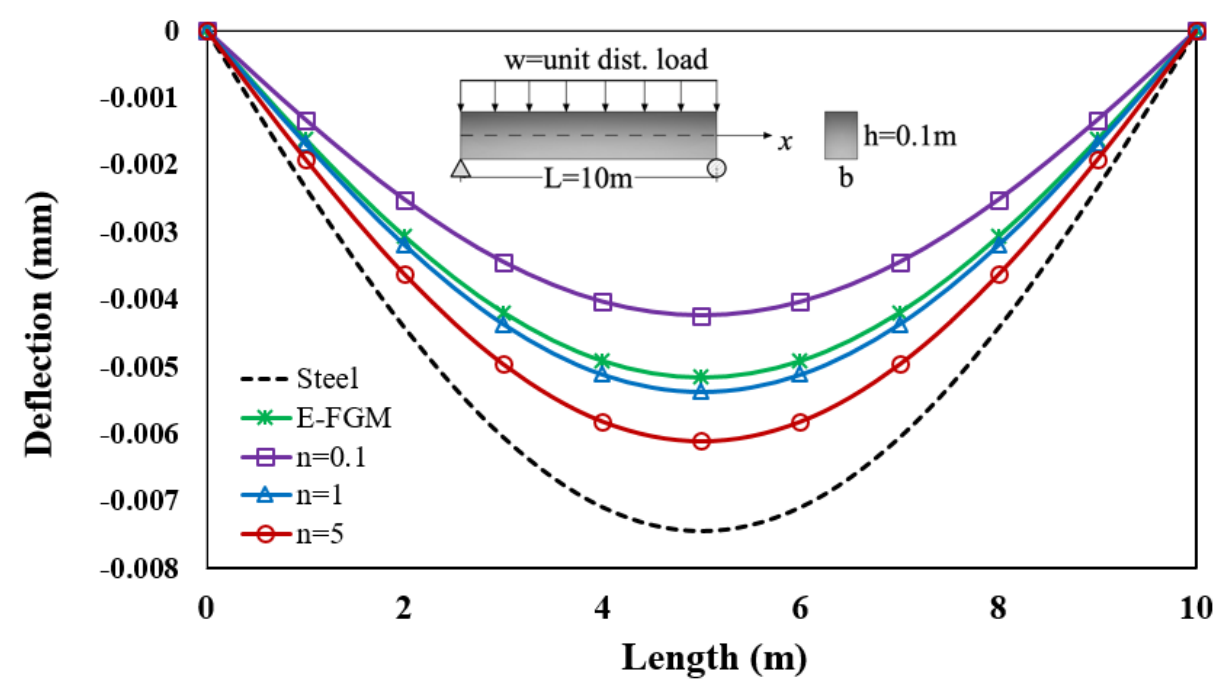

Figure 9. Deflection of a simply supported FGM beam.

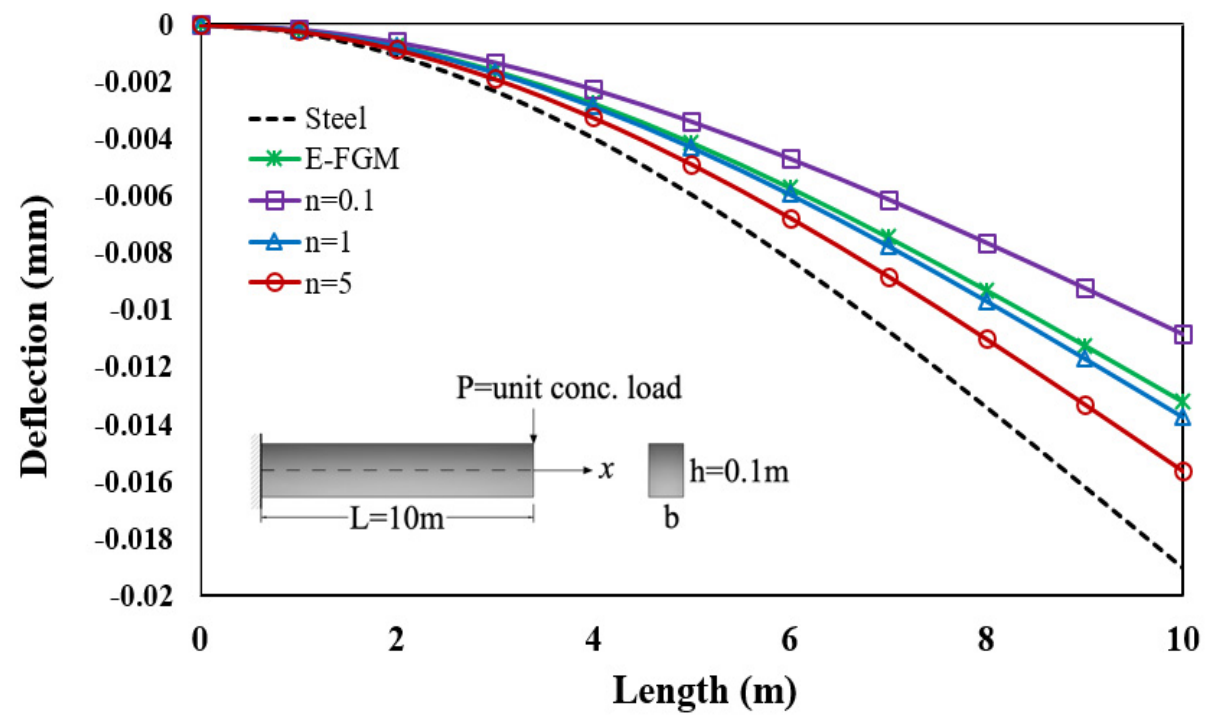

Figure 10. Deflection of cantilever FGM beam.

Numerical FGM Beam Deflection Example

Deflection on the FGM beam is evaluated by double integrating Equation (37). The flexural rigidity of the FGM beam can be evaluated using Equation (38) for each material function and index parameter. For P-FGM, substituting $\mathrm{E}_{1}=390 \mathrm{GPa}$ (ceramic) and $\mathrm{E}_{2}=210 \mathrm{GPa}$ (steel) and solving the stiffness coefficients from Equations (34)-(36), the FGM beam rigidity can be obtained. For a uniformly distributed unit load of $\mathrm{w}=1 \mathrm{kN} / \mathrm{m}$, the moment at any distance from the left support can be expressed as:

$$
M(x)=\frac{w L}{2} x-\frac{w x^{2}}{2}
$$


Deflection equation along a simply supported FGM beam can be simplified as similar to the well-known isotropic-homogenous beam deflection except for the beam rigidity.

$$
\delta(\mathrm{x})=\frac{\mathrm{wx}}{24 \widetilde{\mathrm{D}}}\left(\mathrm{L}^{3}-2 \mathrm{Lx}^{2}+\mathrm{x}^{3}\right)
$$

The simply supported FGM beam with E-FGM, P-FGM, and homogenous steel deflections from the unit distributed load are presented in Table 3.

Table 3. Simply supported FGM beam deflection.

\begin{tabular}{cccccc}
\hline Length (m) & Steel & E-FGM & $\mathbf{n}=\mathbf{0 . 1}$ & $\mathbf{n}=\mathbf{1}$ & $\mathbf{n}=\mathbf{5}$ \\
\hline 0 & 0.0000 & 0.0000 & 0.0000 & 0.0000 & 0.0000 \\
1 & -0.0023 & -0.0016 & -0.0013 & -0.0017 & -0.0019 \\
2 & -0.0044 & -0.0031 & -0.0025 & -0.0032 & -0.0036 \\
3 & -0.0061 & -0.0042 & -0.0034 & -0.0044 & -0.0050 \\
4 & -0.0071 & -0.0049 & -0.0040 & -0.0051 & -0.0058 \\
5 & -0.0074 & -0.0052 & -0.0042 & -0.0054 & -0.0061 \\
6 & -0.0071 & -0.0049 & -0.0040 & -0.0051 & -0.0058 \\
7 & -0.0061 & -0.0042 & -0.0034 & -0.0044 & -0.0050 \\
8 & -0.0044 & -0.0031 & -0.0025 & -0.0032 & -0.0036 \\
9 & -0.0023 & -0.0016 & -0.0013 & -0.0017 & -0.0019 \\
10 & 0.0000 & 0.0000 & 0.0000 & 0.0000 & 0.0000 \\
\hline
\end{tabular}

It can be noted that the maximum deflections were observed in the steel beam compared to the FGM beams. Also, amongst the material function, the P-FGM with index $\mathrm{n}=0.1$ resulted in the least deflection. This observation can lead to an optimized material function in FGM beam structural application, especially in terms of deflection.

\section{Conclusions}

A simplified analytical formulation for functionally graded beam stresses analysis and optimization of material function for deflection were presented. The material properties in the FGM beam were assumed to vary in the thickness direction using power-law (P-FGM) and exponential function (E-FGM) material functions. The FE model was also conducted using ABAQUS and some of the results obtained were validated by comparing with literature. The following observations were drawn from the results of the analysis:

- The non-dimensional normal stress and shear stress are independent of the actual elastic moduli values but rather depend on the ratio of E1/E2 and the location across the beam thickness (z) for the E-FGM model.

- The maximum normalized shear stress is located at the neutral axis locations for each E1/E2 considered. Moreover, the normalized shear stress is 1.5 times the average shear stress for $\mathrm{E} 1=\mathrm{E} 2$, which is consistent with the classical beam theory. However, this maximum ratio is 1.68, 1.55, 1.49, and 1.62 for $\mathrm{E} 1 / \mathrm{E} 2=10, \mathrm{E} 1 / \mathrm{E} 2=5, \mathrm{E} 1 / \mathrm{E} 2=0.5$, and $\mathrm{E} 1 / \mathrm{E} 2=0.1$, respectively.

- That the maximum shear stress for each power-law index value considered corresponds at the neural axis location along with the beam thickness. The maximum and minimum normalized shear stress are observed for $n=0.1$ and $n=2.0$ with 1.45 and 1.14 times the average shear, respectively.

- The maximum deflection on the FGM beam occurred for a homogenous steel beam while the minimum deflection is for P-FGM with power-law index value $\mathrm{n}=0.1$ while E-FGM showed the second-lowest deflection in both simply supported and cantilever beams.

The observations and findings in this paper considered only E-FGM and P-FGM material functions. Future studies need to include the S-FGM material function to derive a similar simplified stress analysis solution, perform more parametric studies including 
different loading types, boundary conditions, and optimization of material functions for both stress and deflection requirements of FGM beams.

Author Contributions: Conceptualization, E.A.; methodology, E.A.; software, E.A.; validation, F.A., writing —original draft preparation, E.A.; writing—review and editing, F.A. All authors have read and agreed to the published version of the manuscript.

Funding: This research received no external funding.

Institutional Review Board Statement: Not applicable.

Informed Consent Statement: Not applicable.

Data Availability Statement: Not applicable.

Conflicts of Interest: The authors declare no conflict of interest.

\section{References}

1. Mahamood, R.M.; Akinlabi, E.T. Functionally Graded Material: An Overview. In Proceedings of the World Congress on Engineering, London, UK, 4-6 July 2012.

2. Sankar, B.V. An elasticity solution for functionally graded beams. Compos. Sci. Technol. 2001, 61, 689-696. [CrossRef]

3. Chakraborty, A.; Gopalakrishnan, S.; Reddy, J.N. A new beam finite element for the analysis of functionally graded materials. Int. J. Mech. Sci. 2003, 45, 519-539. [CrossRef]

4. Zhu, H.; Sankar, B.V. A Combined Fourier Series-Galerkin Method for the Analysis of Functionally Graded Beams. J. App. Mech. 2004, 71. [CrossRef]

5. Alshorbagy, A.E.; Eltaher, M.A.; Mahmoud, F.F. Free vibration characteristics of a functionally graded beam by finite element method. App. Math. Mod. 2011, 35, 412-425. [CrossRef]

6. Ziou, H.; Guenfoud, H.; Guenfoud, M. Numerical modeling of a Timoshenko FGM beam using the finite element method. Int. J. Struct. Eng. 2016, 7, 239-261. [CrossRef]

7. Kadoli, R.; Akhtar, K.; Ganesan, N. Static analysis of functionally graded beams using higher order shear deformation theory. App. Math. Mod. 2008, 32, 2509-2525. [CrossRef]

8. Zhang, D.-G. Nonlinear bending analysis of FGM beams based on physical neutral surface and high order shear deformation theory. Compos. Struct. 2013, 100, 121-126. [CrossRef]

9. Rezaiee-Pajand, M.; Masoodi, A.R. Exact natural frequencies and buckling load of functionally graded material tapered beamcolumns considering semi-rigid connections. J. Vib. Cont. 2016, 24, 1787-1808. [CrossRef]

10. Rezaiee-Pajand, M.; Rajabzadeh-Safaei, N.; Masoodi, A.R. An efficient curved beam element for thermo-mechanical nonlinear analysis of functionally graded porous beams. Structures 2020, 28, 1035-1049. [CrossRef]

11. Rezaiee-Pajsnd, M.; Sobhani, E.; Masoodi, A.R. Semi-analytical vibrational analysis of functionally graded carbon nanotubes coupled conical-conical shells. Thin-Walled Struct. 2021, 159, 107272. [CrossRef]

12. Li, S.-R.; Cao, D.-F.; Wan, Z.-Q. Bending solutions of FGM Timoshenko beams from those of the homogenous Euler-Bernoulli beams. App. Math. Mod. 2013, 37, 7077-7085. [CrossRef]

13. Jiao, P.; Wang, Y.; Xu, G.; Zhang, F.; Yuan, Q.; You, W. Linear bending of functionally graded beams by differential quadrature method. Earth Environ. Sci. 2018, 170. [CrossRef]

14. Birsan, M.; Altenbach, H.; Sadowski, T.; Eremeyev, V.A.; Pietras, D. Deformation analysis of functionally graded beams by the direct approach. Compos. Struct. 2013, 43, 1315-1328. [CrossRef]

15. Ali, E.; Woldeyes, K.; Urgessa, G. Fire performance of functionally-graded-material sheathed load bearing thin-walled structural framing. J. Fire Saf. 2021, 125, 103425. [CrossRef]

16. Ali, E.Y.; Shifferaw, Y. Application of the direct strength method to functionally-graded-material-sheathed cold-formed steel beam channel members under non-uniform elevated temperature. In Proceedings of the Structural Stability Research Council Annual Stability Conference, Baltimore, MD, USA, 10-13 April 2018.

17. Muc, A.; Flis, J. Flutter characteristics and free vibrations of rectangular functionally graded porous plates. Compos. Struct. 2021, 261, 113301. [CrossRef]

18. Muc, A.; Flis, J.; Augustyn, M. Optimal Design of Plated/Shell Structures under Flutter Constraints-A Literature Review. Materials 2019, 12, 4215. [CrossRef] [PubMed]

19. Muc, A. Optimizing the Thickness/Stiffness Distribution of Infinitely Wide Porous FGM Plates Subjected To Supersonic Flutter Constraints. Mech. Compos. Mater. 2021, 56, 713-720. [CrossRef]

20. Ali, E.Y.; Bayleyegn, Y.S. Analytical and numerical buckling analysis of rectangular functionally-graded plates under uniaxial compression. In Proceedings of the Structural Stability Research Council Annual Stability Conference, St. Louis, MO, USA, 2-5 April 2019.

21. Zhao, L.; Gan, W. Analytical Solutions for Functionally Graded Beams under Arbitrary Distributed Loads via the Symplectic Approach. Adv. Mech. Eng. 2015, 7, 321263. [CrossRef] 
22. Abanto-Bueno, J.; Lambros, J. Investigation of crack growth in functionally graded materials using digital image correlation. Eng. Fra. Mech. 2002, 69, 1695-1711. [CrossRef]

23. Yang, Q.; Zheng, B.; Zhang, K.; Zhu, J. Analytical solution of a bilayer functionally graded cantilever beam with concentrated loads. Arch. Appl. Mech. 2012, 83, 455-466. [CrossRef]

24. Chung, Y.L.; Chi, S.H. The residual stress of functionally graded materials. J. Chi. Inst. Civil Hyd. Eng. 2001, 13, 1-9.

25. Bao, G.; Wang, L. Multiple cracking in functionally graded ceramic/metal coatings. Int. J. Sol. Struct. 1995, 32, 2853-2871. [CrossRef]

26. Sharifishourabi, G.; Ayob, A.; Gohari, S.; Yahya, M.; Sharifi, S.; Vrcelj, Z. Flexural behavior of functionally graded slender beams with complex cross-section. J. Mech. Mat. Struct. 2015, 10, 1-16. [CrossRef] 